\title{
A New Murine Liver Fibrosis Model Induced by Polyhexamethylene Guanidine-Phosphate
}

\author{
Minjeong Kim ${ }^{1, \dagger}$, Sumin $\mathrm{Hur}^{2, \dagger}$, Kwang H. Kim², Yejin $\mathrm{Cho}^{2}$, Keunyoung Kim², Ha Ryong Kim ${ }^{4}$ Ki Taek Nam ${ }^{2, *}$ \\ and Kyung-Min Lim ${ }^{1, *}$ \\ ${ }^{1}$ College of Pharmacy, Ewha Womans University, Seoul 03760, \\ ${ }^{2}$ Severance Biomedical Science Institute, Brain Korea 21 PLUS Project for Medical Science, College of Medicine, Yonsei University, \\ Seoul 03722, \\ ${ }^{3}$ College of Pharmacy, Kangwon National University, Chuncheon 24341, \\ ${ }^{4}$ College of Pharmacy, Daegu Catholic University, Daegu 38430, Republic of Korea
}

\begin{abstract}
Liver fibrosis is part of the wound healing process to help the liver recover from the injuries caused by various liver-damaging insults. However, liver fibrosis often progresses to life-threatening cirrhosis and hepatocellular carcinoma. To overcome the limitations of current in vivo liver fibrosis models for studying the pathophysiology of liver fibrosis and establishing effective treatment strategies, we developed a new mouse model of liver fibrosis using polyhexamethylene guanidine phosphate (PHMG-p), a humidifier sterilizer known to induce lung fibrosis in humans. Male C57/BL6 mice were intraperitoneally injected with PHMG-p $(0.03 \%$ and $0.1 \%)$ twice a week for 5 weeks. Subsequently, liver tissues were examined histologically and RNA-sequencing was performed to evaluate the expression of key genes and pathways affected by PHMG-p. PHMG-p injection resulted in body weight loss of $\sim 15 \%$ and worsening of physical condition. Necropsy revealed diffuse fibrotic lesions in the liver with no effect on the lungs. Histology, collagen staining, immunohistochemistry for smooth muscle actin and collagen, and polymerase chain reaction analysis of fibrotic genes revealed that PHMG-p induced liver fibrosis in the peri-central, peri-portal, and capsule regions. RNA-sequencing revealed that PHMG-p affected several pathways associated with human liver fibrosis, especially with upregulation of lumican and IRAK3, and downregulation of GSTp1 and GSTp2, which are closely involved in liver fibrosis pathogenesis. Collectively we demonstrated that the PHMG-p-induced liver fibrosis model can be employed to study human liver fibrosis.
\end{abstract}

Key Words: Liver fibrosis, Polyhexamethylene guanidine phosphate (PHMG-p), Murine liver fibrosis model, Lumican, IRAK3

\section{INTRODUCTION}

Hepatocellular carcinoma (HCC) is one of the major causes of death worldwide. Liver fibrosis and cirrhosis arising from liver injury caused by alcohol abuse, HBV infection, parasitic infection, and metabolic syndromes account for $60-76 \%$ of HCC cases (Schuppan and Afdhal, 2008). However, the pathway linking liver injury to liver fibrosis is not yet fully established; thus, efforts have been made to understand the pathological mechanism of hepatic fibrogenesis (Ismail and Pinzani, 2009).

Normally, when the insult causing the liver injury is removed, the liver undergoes repair, and regenerates. However, the persistence of liver-damaging insults and repeated liver injury can trigger chronic hepatitis and fibrosis, which may progress to liver cirrhosis or HCC (Ismail and Pinzani, 2009). Liver fibrosis is considered a wound-healing process characterized by excessive accumulation of collagen fiber in the liver sinusoid. Kupffer cells are activated following hepatocyte injury, leading to the secretion of pro-inflammatory cytokines such as transforming growth factor (TGF)- $\beta$ and platelet-derived growth factor (PDGF), and the generation of reactive oxygen species (ROS) as a consequence of parenchymal cell death, which eventually stimulates hepatic stellate cells (HSCs). During this process, complex interactions occur among hepatocytes, HSCs, Kupffer cells, neutrophils, and monocytes, which culminate in the emergence of myofibroblasts (Albanis and Fried-
Open Access https://doi.org/10.4062/biomolther.2021.120

This is an Open Access article distributed under the terms of the Creative Commons Attribution Non-Commercial License (http://creativecommons.org/licenses/by-nc/4.0/) which permits unrestricted non-commercial use, distribution, and reproduction in any medium, provided the original work is properly cited.
Received Jul 16, 2021 Revised Aug 12, 2021 Accepted Aug 13, 2021 Published Online Sep 28, 2021

\section{*Corresponding Authors}

E-mail:kmlim@ewha.ac.kr (Lim KM), kitaek@yuhs.ac (Nam KT) Tel: +82-2-3277-3055 (Lim KM), +82-2-2228-0754 (Nam KT) Fax: +82-2-3277-3760 (Lim KM), +82-2-2227-8129 (Nam KT) ${ }^{\dagger}$ The first two authors contributed equally to this work. 
man, 2006). Activated myofibroblasts and fibroblasts residing in the liver secrete alpha-smooth muscle actin ( $\alpha$-SMA) and extracellular matrix (ECM) molecules such as collagen (COL1a1 and COL1a3) and tissue inhibitor of metalloproteinase 1 (TIMP1), which form the primary fiber structure of liver fibrosis.

Several animal models of liver fibrosis have been developed employing chemical and mechanical liver injury insults. The chemical insults used for causing acute liver injury include treatment with calcium tetrachloride $\left(\mathrm{CaCl}_{4}\right)$ (elSisi et al., 1993), dimethylnitrosamine (Yasuda et al., 1999), 3,5-diethoxycarbonyl-1,4-dihydrocollidine, and chlorhexidine digluconate. Alcohol and $\mathrm{CCl}_{4}$ treatment have also been used to induce chronic liver injury. Mechanical insults such as bile duct ligation have been successfully used to induce liver injury, which can progress to liver fibrosis. However, each liver fibrosis model has its advantages and drawbacks. For instance, liver fibrosis can take up to 8-12 weeks with $\mathrm{CCl}_{4}$, thioacetamide, ally alcohol, porcine serum, or schistosomiasis. Although the dimethylnitrosamine model can be established within 4 weeks it is a potent hepatotoxin, carcinogen, and mutagen (George et al., 2019).

The origin of myofibroblasts in the induced fibrotic liver may differ among fibrosis models (Iwaisako et al., 2014; Lua et al., 2016), which makes it difficult to generalize the experimental results to different types of human fibrosis. For instance, in rodent models of liver damage, HSCs are the main source of myofibroblasts (Mederacke et al., 2013), whereas portal fibroblasts in the periportal region, which strongly express COL1a1 and $\alpha$-SMA, are the major contributors to myofibroblasts in the fibrosis model induced by bile duct ligation (Iwaisako et al., 2014). Mesothelial cells on the liver surface may also give rise to myofibroblasts via the mesothelial-mesenchymal transition in the $\mathrm{CCl}_{4}$ liver injury model, mouse bile duct ligation damage model, or DDC-induced model (Li et al., 2013; Lua et al., 2016; Balog et al., 2020), adding more complexity to the interpretation of the experimental results. Therefore, a new model of liver fibrosis relevant to human liver fibrosis is needed to advance research in this field.

In this study, we investigated whether the intraperitoneal (i.p.) injection of polyhexamethylene guanidine-phosphate (PHMG-p) can induce liver fibrosis in C57/BL6 mice. PHMG$p$ was originally developed as a carpet-decontaminating biocide and is found in several humidifier disinfectants; although it's a strong skin irritant, its oral toxicity is low. However, the use of PHMG-p was shown to provoke pulmonary fibrosis, claiming hundreds of lives in Korea (Park, 2013; Kim et al., 2016; Song et al., 2021). Kim et al. demonstrated that PHMG$p$ induces the generation of reactive oxygen species (ROS), which causes epithelial damage and inflammation (Kim et al., 2016). Interestingly, Russians who consumed an illegal vodka product containing PHMG died from hepatitis and cholestasis accompanying fibrosis (Solodun et al., 2011; Asiedu-Gyekye et al., 2014), suggesting that PHMG-p can also induce liver injury and liver fibrosis in humans.

We intraperitoneally injected PHMG-p in C56/BL7 mice twice a week for 5 weeks and examined the associated morbidity and mortality as well as the induction of liver fibrosis by histologically and immunohistochemically analyzing the fibrotic markers. We performed RNA-sequencing to analyze the genomic changes induced by PHMG to examine its applicability as a model of human liver fibrosis.

\section{MATERIALS AND METHODS}

\section{Animals and PHMG-p treatment}

C57/BL6 male mice were purchased from Orient Bio (Seongnam, Korea) and managed in a specific-pathogen free facility of University of Yonsei (Seoul, Korea). All animal experiments were conducted in accordance with the Public Health Service Policy in Humane Care and Use of Laboratory Animals and were approved by the IACUC (2019-0183), an AAALAC-accredited unit (\#001071). PHMG-P was provided by the Korea Institute of Toxicology (KIT, Jeongeup, Korea). Stock solutions of PHMG-p (1\% in distilled water) were diluted with DW to $0.1 \%$ and $0.03 \%$ based upon a preliminary toxicity test. Mice (6 weeks old with the body weight of $\sim 25 \mathrm{~g}$ at the start of dosing) were injected i.p. with each PHMG-p solution at $5 \mathrm{~mL} / \mathrm{kg}(\sim 100 \mu \mathrm{L} /$ a mouse, i.e., $1.5 \mathrm{mg} / \mathrm{kg}$ and $4.5 \mathrm{mg} / \mathrm{kg})$ twice weekly for 5 weeks at the interval of 3-4 days. The control group received injection of DW (Supplementary Fig. 1A).

\section{Histology and immunohistochemistry}

Paraformaldehyde-fixed and paraffin-embedded tissues were cut into $5 \mu \mathrm{m}$ thick sections, subjected to xylene deparaffinization, rehydration, heat-induced epitope retrieval, and blocking, and stained with hematoxylin and eosin, Picro-Sirius Red Stain (Kit for Collagen, Scytek, West Logan, UT, USA), and Collagen Hybridizing Peptide (R-CHP, 3HELIX, Salt Lake City, UT, USA). The slides were incubated overnight at $4^{\circ} \mathrm{C}$ with the relevant primary and secondary antibodies, and the signals were developed with DAB substrate ( $k 3468$, DAKO, Santa Clara, CA, USA) using ABC kit (VECTORSTAIN Elite ABC kit, Vector Laboratories, Inc., Burlingame, CA, USA). The immunohistochemistry slides were scanned using Easy Scan (Motic, Barcelona, Spain). Image analysis was performed using a Qupath program (University of Edinburgh, Edinburgh, Scotland).

\section{RNA-sequencing}

Total RNA was isolated from the liver samples $(\mathrm{N}=4$ per each group) collected from the same liver lobe of animals using Trizol reagent (Invitrogen, Carlsbad, CA, USA). RNA quality was assessed using an Agilent 2100 bioanalyzer and a RNA 6000 NanoChip (Agilent Technologies, Amstelveen, the Netherlands). RNA was quantified spectrophotometrically (ND 2000, Thermo Inc., DE, USA).

The libraries of control and test RNAs were constructed using QuantSeq 3 mRNA Seq Library Prep Kit (Lexogen, Inc., Vienna, Austria). High-throughput sequencing was performed as single-end 75 sequencing using Next Seq 500 (Illumina, Inc. San Diego, CA, USA).

QuantSeq 3 mRNA Seq reads were aligned using Bowtie2 (Langmead and Salzberg, 2012). Bowtie2 indices were either generated from the genome assembly sequence or the representative transcript sequences for aligning to the genome and transcriptome. The alignment file was used for assembling transcripts, estimating their abundances, and detecting differentially expressed genes (fold change $\geq 2, p<0.05$ ) based on counts from unique and multiple alignments using coverage in Bedtools (Quinlan and Hall, 2010). Read data were processed based on the quantile normalization method using Edge R with Bioconductor (Gentleman et al., 2004). 


\section{Clustering and bioinformatic analysis}

Hierarchical clustering was performed using MeV 4.9.0 (Saeed et al., 2003). Gene classification was based on searches with DAVID functional annotation tool (https://david.ncifcrf.gov/summary.jsp/) (Jiao et al., 2012) and Medline databases (http://www.ncbi.nlm.nih.gov/). Pathways were annotated with Kyoto Encyclopedia of Genes and Genomes (KEGG) mapper (http://www.genome.jp/kegg/tool/map_pathway2.html/) (Kanehisa and Goto, 2000) and protein-protein interactions were evaluated with the Search Tool for the Retrieval of Interacting Genes/Proteins (STRING) database. We then used the Cytoscape app ClueGO to identify biological processes in which the selected genes were involved to identify important functions (Bindea et al., 2009). Details of these analyses are provided in the Supplemental Data.

\section{Real-time PCR}

The liver samples were lysed using Trizol (Invitrogen). After the addition of chloroform, the samples were centrifuged at $12,000 \mathrm{rpm}$ for $10 \mathrm{~min}$. The aqueous phase was mixed with isopropanol and RNA pellets were obtained by centrifugation $\left(12,000 \mathrm{rpm}, 15 \mathrm{~min}, 4^{\circ} \mathrm{C}\right)$, washed with $70 \%$ ethanol, and dissolved in RNase-free, diethylpyrocarbonate-treated water. The RNA yield was determined using a NanoDrop 1000 spectrophotometer (NanoDrop Technologies, Inc., Wilmington, DE, USA).
Relative expression levels of mRNAs were measured by performing quantitative PCR. The left lateral lobe of the liver was perfused with PBS and soaked in ice-cold RNAlater. After overnight incubation at $4^{\circ} \mathrm{C}$, the samples were stored at $-70^{\circ} \mathrm{C}$. The cDNA was synthesized from $1,250 \mathrm{ng}$ total RNA using oligo(dT) (Bioelpis, Seoul, Korea) and SYBR Green PCR master mix on a StepOnePlusTM Real-time PCR machine (Applied Biosystems, Warrington, UK). The primer sequences are listed in Supplementary Table 1. Cycling parameters were $51^{\circ} \mathrm{C}$ for $2 \mathrm{~min}, 95^{\circ} \mathrm{C}$ for $10 \mathrm{~min}, 40$ cycles of $95^{\circ} \mathrm{C}$ for $15 \mathrm{~s}$, and $51^{\circ} \mathrm{C}$ for $1 \mathrm{~min}$.

\section{Statistical analysis}

Statistical analysis was performed using Graphpad prism (software v7.0, Graph pad, San Diego, CA, USA). Statistical significance was determined using unpaired Student's t-test (two-tailed) or one-way analysis of variance with Dunnett's multiple comparison. Data are presented as the mean \pm SEM; $p<0.05$ was considered significant.

\section{RESULTS}

\section{Effects of PHMG-p on body weight change and gross examination at necropsy}

Decreased body weight gain and a rough haircoat were
A

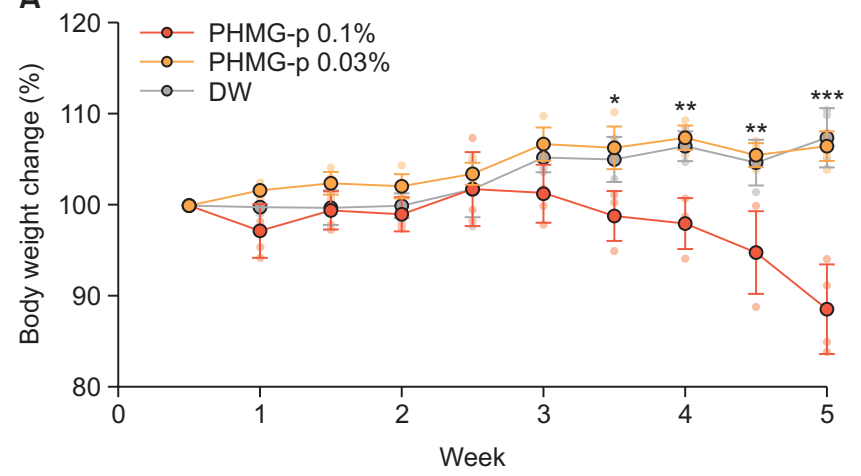

C

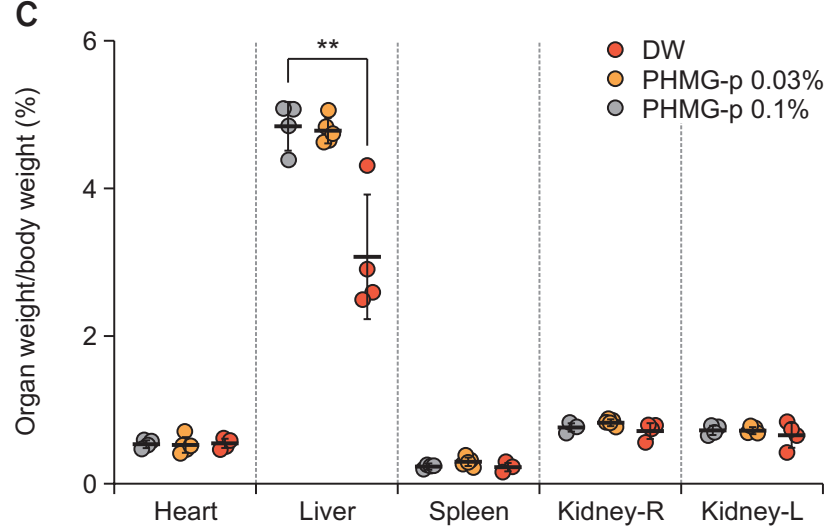

B

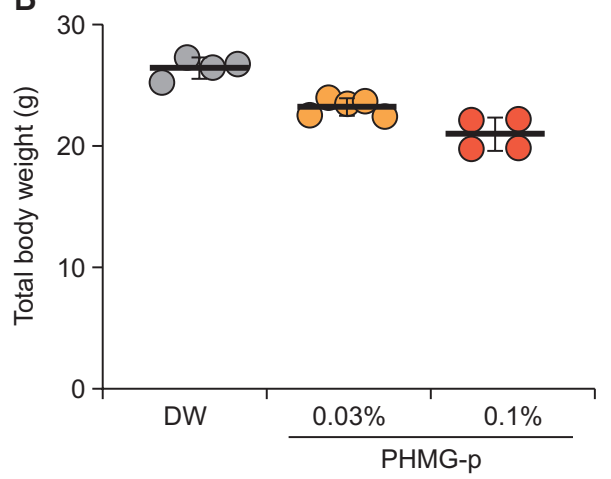

D

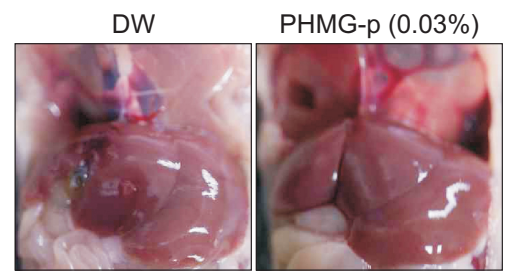

PHMG-p (0.1\%)

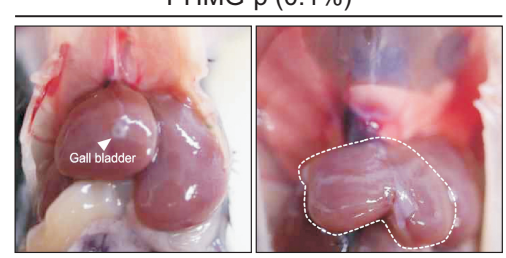

Fig. 1. Intraperitoneal administration of PHMG-p induces weight loss and liver fibrosis phenotype in C57/BL6 mice. (A) Body weight percentage (\%), (B) body weight, and (C) tissue weight/body weight (\%) of C57/BL6 mice at the necropsy. (D) Gross appearance of a representative liver in control (upper left), PHMG-p 0.03\%-treated (upper right), and PHMG-p 0.1\%-treated (bottom) mice. Values indicate mean \pm SE of $4-5$ animals. ${ }^{*} p<0.05,{ }^{* *} p<0.01$ and ${ }^{* * *} p<0.001$. 
observed in the PHMG-p 0.1\% (4.5 mg/kg twice weekly i.p.) group after three weeks, which persisted until the animals were euthanized (after 5 weeks of dosing, Fig. $1 \mathrm{~A}$ and Supplementary Fig. 1A). In contrast, the mice in the PHMG-p 0.03\% group $(1.5 \mathrm{mg} / \mathrm{kg}$ twice weekly i.p.) showed a relatively normal appearance with slightly reduced body weight gain (Fig. 1B, Supplementary Fig. 1B). On the necropsy after 5 weeks of dosing, the PHMG-p $0.1 \%$ group showed a significantly reduced liver weight and gall bladder size, pale and shrunken liver lobe, and attachment of the liver lobes and gall bladder (Fig. 1C, 1D). Strikingly, the liver lobe of the PHMG-p $0.1 \%$ group had a constricted and round shape.
A

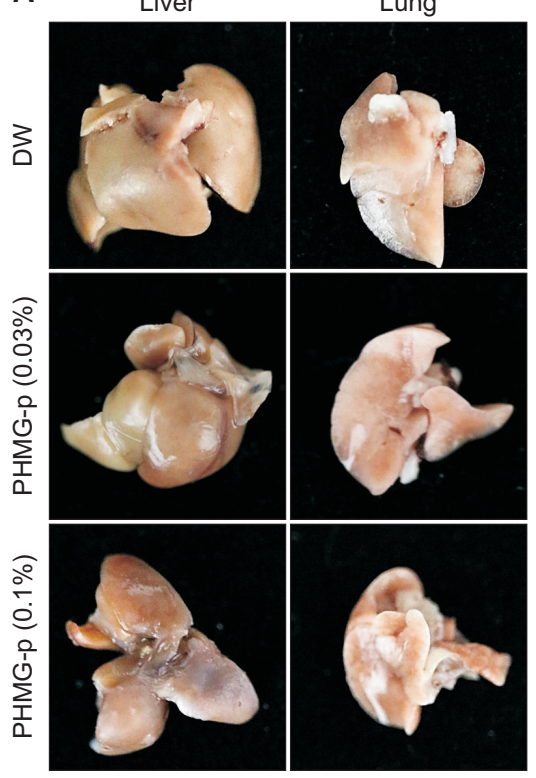

B

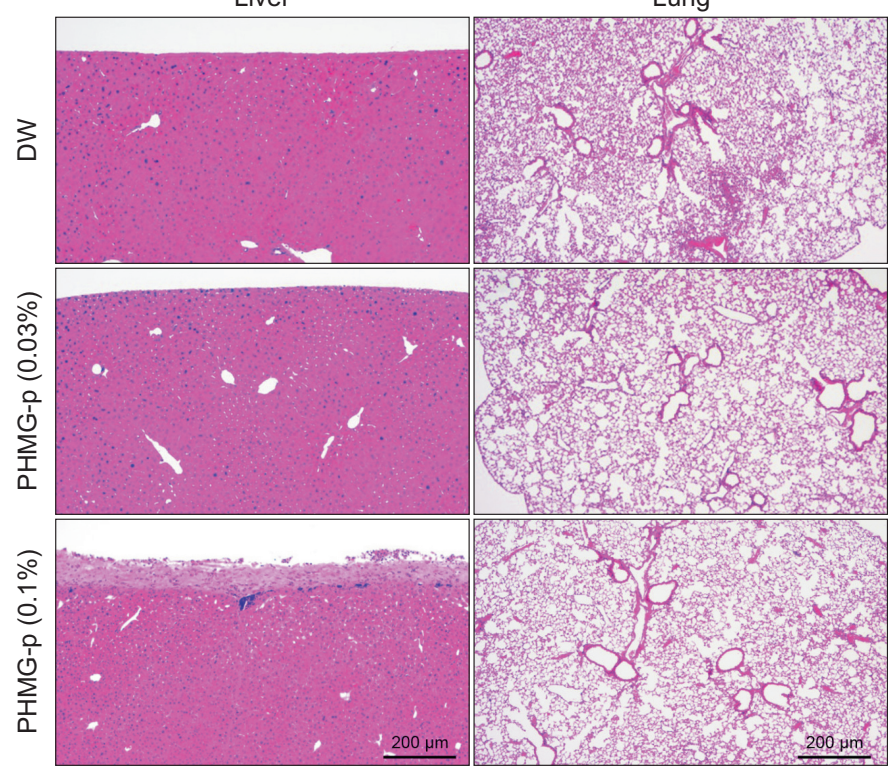

C

DW
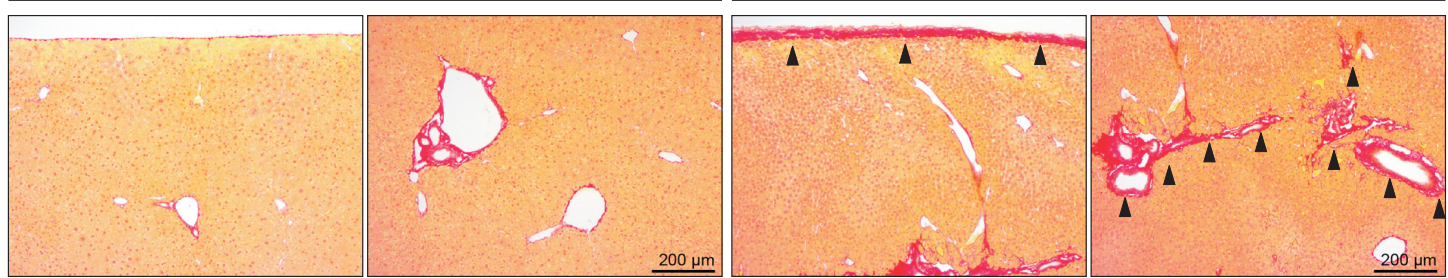

D
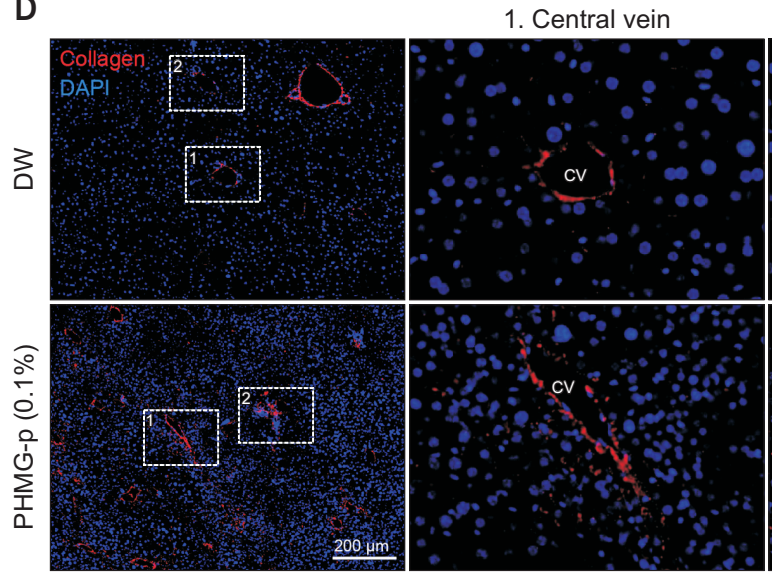

2. Portal vein

Capsule
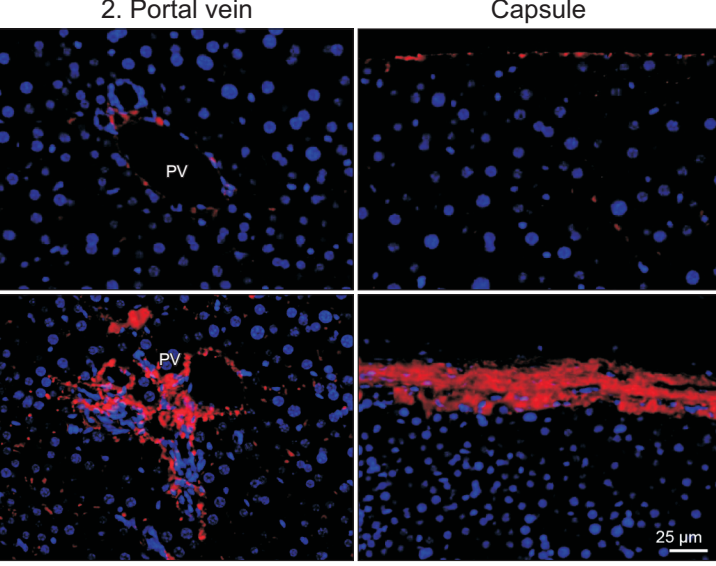

Fig. 2. Liver-specific fibrotic lesion of PHMG-treated mice. (A) Gross morphology and (B) H\&E staining of liver and lung tissues. (C) Sirius red staining for collagen in the liver tissue (Left: Normal lobular architecture and normal distribution of collagen in control mice. Right: Extensive collagen deposition and pseudolobular formation, indicating bridging fibrosis in the PHMG-p 0.1\% group. Scale bar=200 $\mu \mathrm{m})(\mathrm{D})$ Pancollagen-Cy3 immunofluorescence staining. The central vein, portal vein, and capsule regions of the mice are shown. Red=fibrous collagen. 
A

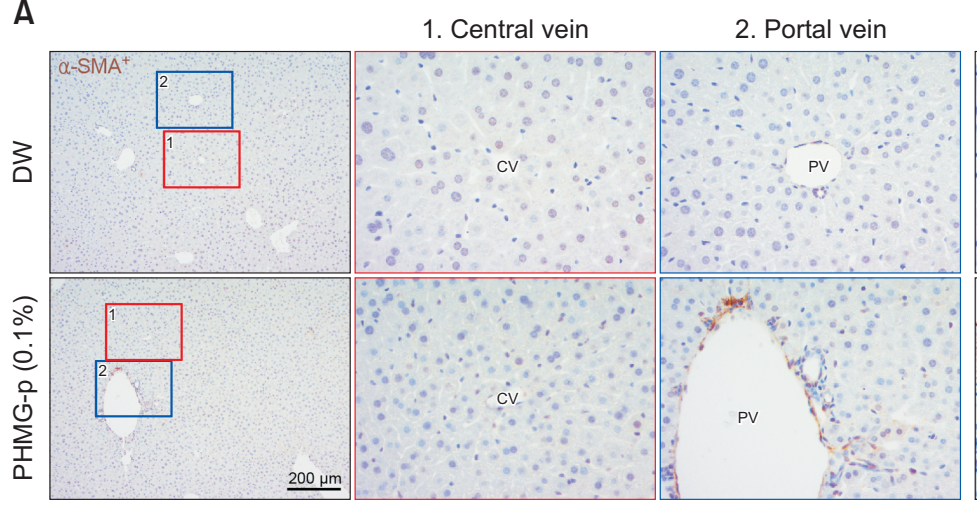

B

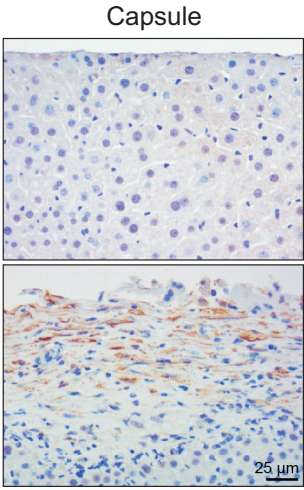

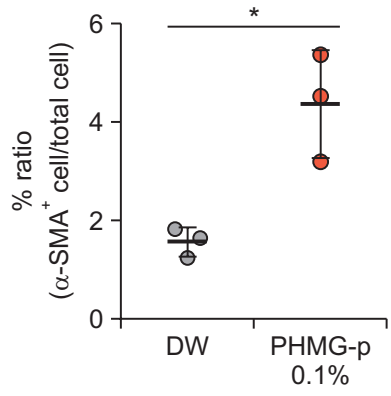

C

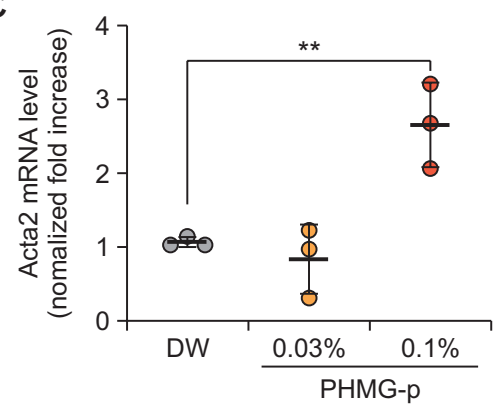

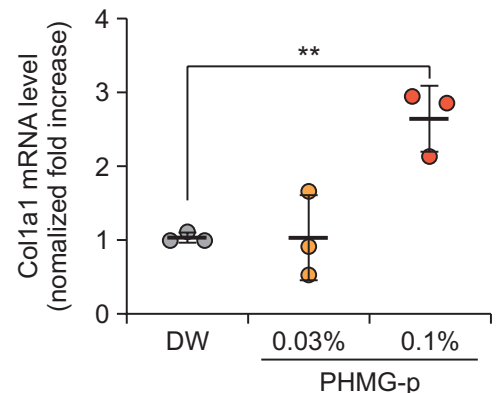

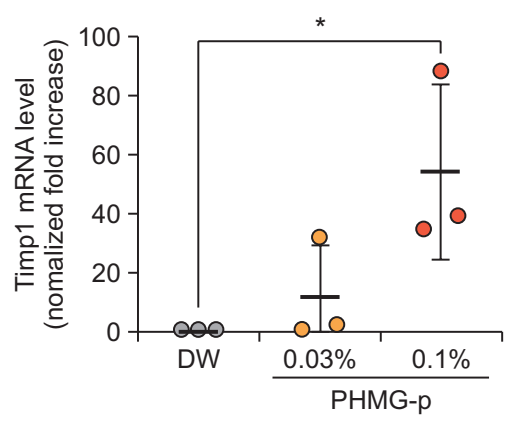

Fig. 3. Fibrotic marker expression. (A) Immunohistochemistry of $\alpha$-smooth muscle actin ( $\alpha$-SMA) in the mice livers, central vein (red box), portal vein (blue box), and capsule regions. Scale bar $=25 \mu \mathrm{m}$. (B) Ratio of $\alpha$-SMA positive cells/hematoxylin (\%), (C) Real-time PCR to detect the expression levels of Acta2, Col1a1, and Timp1. Values are normalized to glyceraldehyde 3-phosphate dehydrogenase (Gapdh) expression levels. Data are presented as the mean $\pm \mathrm{SE}\left(\mathrm{N}=3 ;{ }^{*} p<0.05\right.$ and $\left.{ }^{* *} p<0.01\right)$.

\section{Histopathological examination of the liver of mice exposed to PHMG-p}

Histological examination showed a distinct morphology of liver fibrosis in the PHMG-treated mice, especially around the capsular region (Fig. 2A, 2B). In contrast, no fibrosis was observed in the lungs. Sirius red staining for collagen showed strong staining of the periportal regions as well as the liver capsule of the PHMG-treated mice. Single squamous cells lining the liver surface were stained in the control group, whereas the thicker Glisson's capsule was stained in the PHMG-p $0.1 \%$ group (Fig. $2 \mathrm{C}$ ). Immunofluorescence staining for collagen also substantiated the higher levels of collagen deposition around the portal vein and the capsular fibrosis of the livers of PHMG-treated mice (Fig. 2D). Immunohistochemical analysis of $\alpha$-SMA expression suggested activation of myofibroblasts around the capsule and periportal regions of the PHMGtreated mice compared with DW-treated control mice (Fig. 3A, $3 \mathrm{~B})$. Expression analysis of Acta2 ( $\alpha$-SMA gene), Col1a1, and Timp1 (Fig. 3C) confirmed the development of liver fibrosis following PHMG-p (0.1\%) treatment.

\section{Alteration of gene expression in the liver following PHMG-p treatment}

The volcano plot of the RNA-sequencing data (Fig. 4A, 4B) showed that PHMG-p treatment induced alterations of mRNA expression in a dose-dependent manner. Clustering heatmap analysis (Fig. 4C) based on the expression levels of 2,010 genes (out of 23,282 evaluated genes) whose expression levels were changed significantly ( $>2$-fold) also confirmed altera- tion of the transcriptomic landscape by PHMG-p treatment.

Supplementary Table 2 shows the results of Gene Ontology (GO) term enrichment analysis based on the differentially expressed genes in the liver following PHMG-p 0.1\% treatment. Of the top $30 \mathrm{GO}$ terms identified, the oxidation-reduction process $(p=7.238 \mathrm{E}-19$, false discovery rate $=1.345 \mathrm{E}-15)$ was the most affected pathway, followed by heat generation, and negative regulation of lipid biosynthetic process. Importantly, several of the identified pathways are related to human liver fibrosis as revealed by studies on HSCs, in vivo fibrosis models, or human liver fibrosis tissues (Supplementary Table 2).

\section{Functional network analysis and immunohistochemistry of the liver to identify the key genes}

We selected the 34 genes that were most strongly modulated by PHMG-p in a dose-dependent manner and were related to liver fibrosis, and analyzed their functional network using ClueGO (Supplementary Fig. 2) and STRING (Fig. 5A, 5B).

RNA-sequencing data demonstrated PHMG-p dose-dependent upregulated expression of Acta2, Col1a1, Timp1, lumican (Lum), interleukin 1 receptor, type II (II1r2), interleukin-1 receptor-associated kinase 3 (Irak3), and colony-stimulating factor 2 receptor, beta 2 (Csf2rb2), and dose-dependent downregulated expression of glutathione S-transferase pi 1 (Gstp1) and Gstp2 (Fig. 5C). We further focused on the expression of Lum and Irak3, given their roles in the pathogenesis of liver fibrosis. GSTp1 and GSTp2, which are involved in the prevention of oxidative stress, may also be important for the progression of liver fibrosis. Immunohistochemistry re- 
A

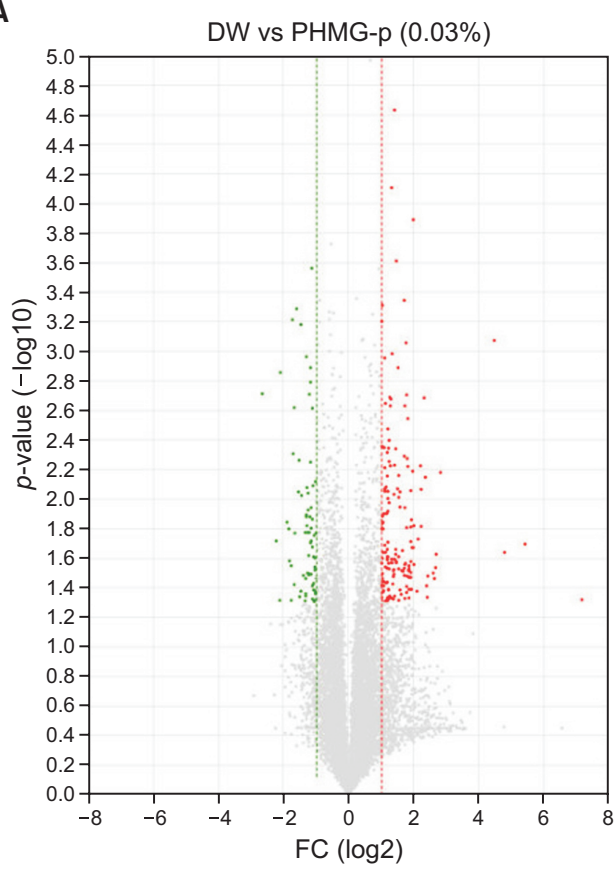

B

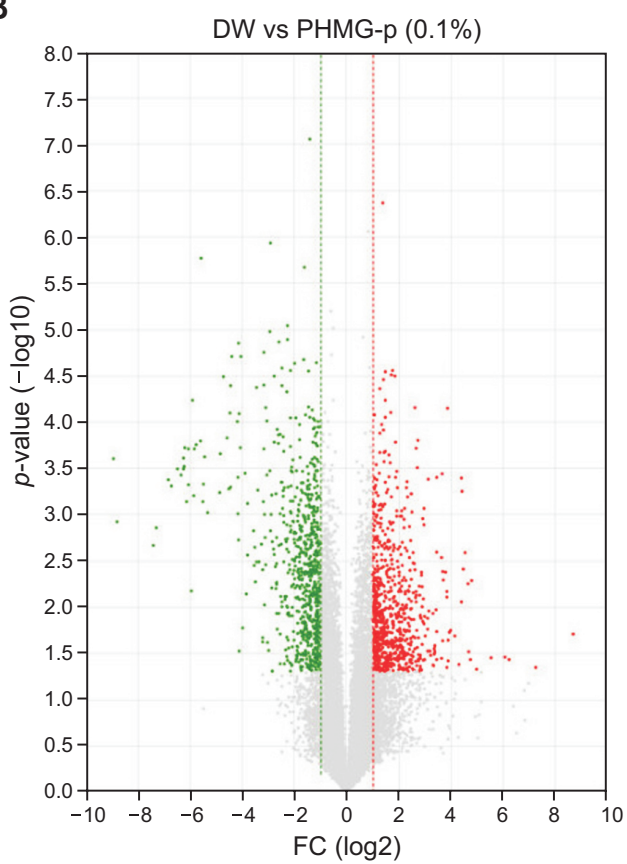

C
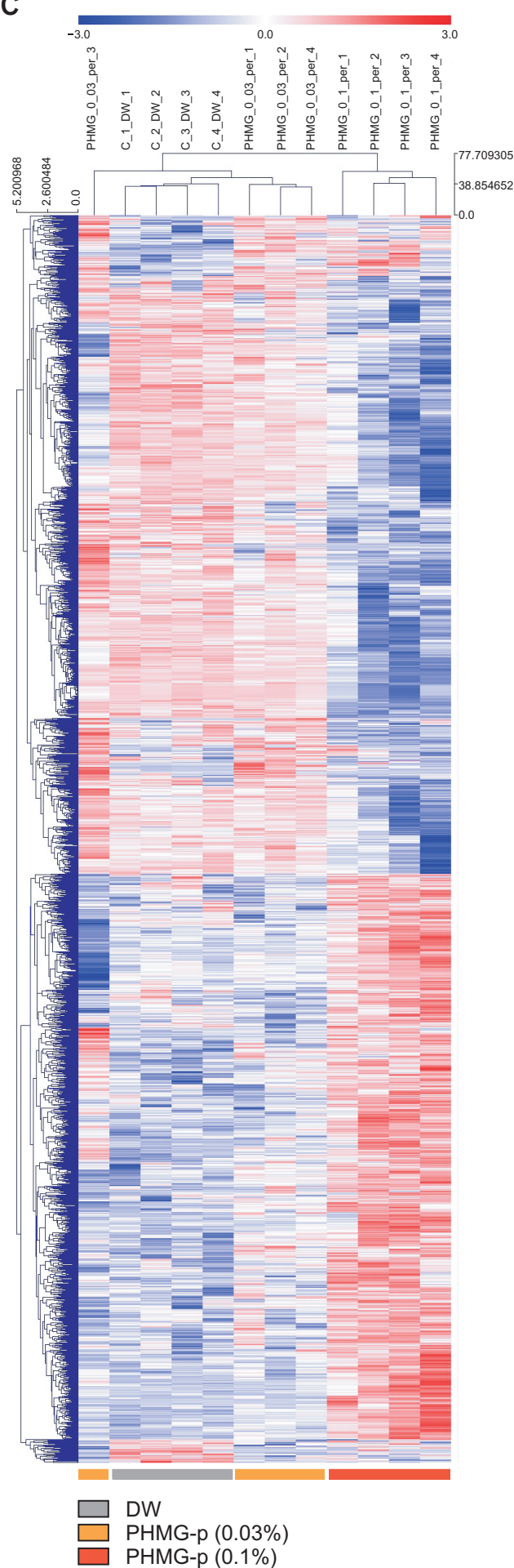

Fig. 4. Genome-wide gene expression profiles of liver tissue altered by PHMG. Volcano plots representing the relationship between the log2 fold change (x-axis) and log10-adjusted $p$-values ( $\mathrm{y}$-axis) obtained from the livers of mice exposed to low (0.03\%) (A) and high (0.1\%) (B) doses of PHMG. (C) Heatmap displaying the normalized signal intensity of read counts following RNA-sequencing transcriptional profiling and clustering of differentially expressed genes between the control, PHMG-p 0.03\%, and PHMG-p 0.1\% groups. Genes with upregulated expression are shown in red and those with downregulated expression are shown in blue as the $\mathrm{z}$-scores (fold change $\geq 2, p<0.05$ ). $\mathrm{N}=4$. 
A

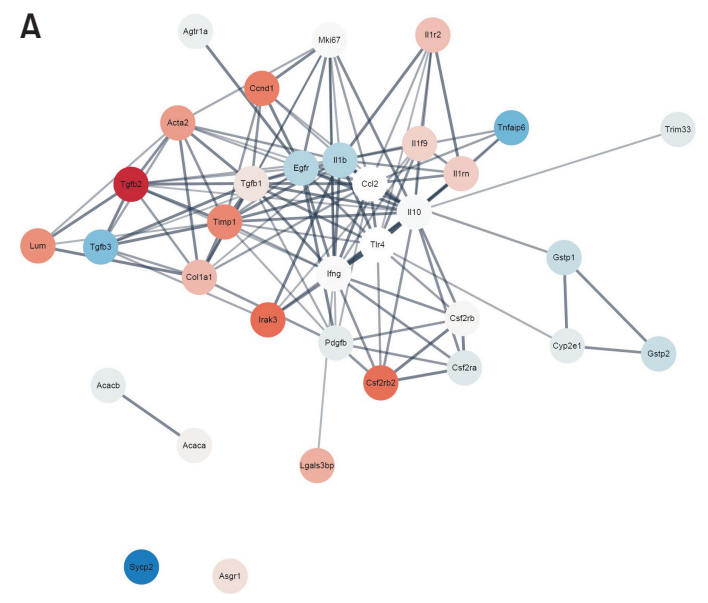

B

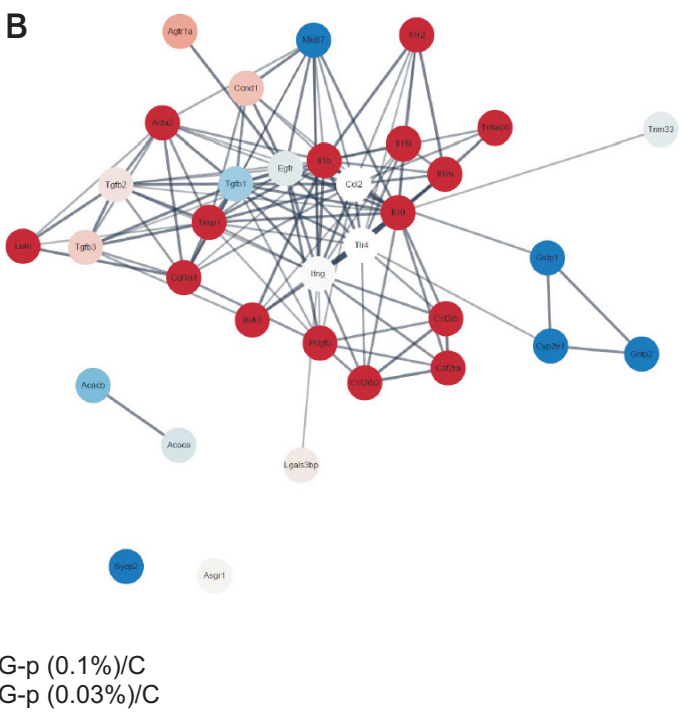

PHMG-p $(0.03 \%) / C$

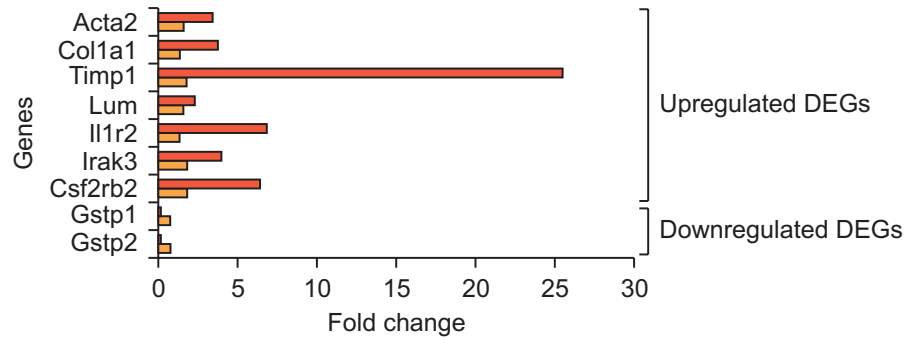

Fig. 5. Functional interaction network and key genes affected by PHMG-p. STRING analysis of the 34 liver fibrosis-associated genes altered by PHMG-p treatment at (A) $0.03 \%$ and (B) $0.1 \%$. Thirty genes formed an interaction network and another two genes interacted with each other with a confidence score cutoff of 0.4 . Colored nodes represent genes; genes with upregulated expression are shown in red and those with downregulated expression are shown in blue. (C) Relative expression levels of key differentially expressed genes (DEGs) determined by RNA-sequencing: Acta2, Col1a1, Timp1, Lum, II1r2, Irak3, Csf2rb2, Gstp1, Gstp2.

sults confirmed that IRAK3 (IRAK-M) and lumican expression was upregulated, whereas GSTp1 expression was downregulated following PHMG-p 0.1\% treatment, in line with the RNAsequencing analysis. In particular, expression of lumican, an ECM protein, increased in the capsular fibrosis region and perivascular region (Fig. 6), whereas the expression of IRAK3 (IRAK-M) strongly increased throughout the liver parenchyma of the PHMG-treated mice. In contrast, the GSTp1 level decreased significantly in the damaged liver hepatocytes.

\section{DISCUSSION}

Here, we demonstrated that repeated i.p. injection of PHMG-p $(0.1 \%, \sim 4.5 \mathrm{mg} / \mathrm{kg})$ can induce liver fibrosis in male C57/BL6 mice. The periportal area and capsule region were the most strongly affected liver parts following PHMG-p induced fibrosis, as confirmed with collagen-Cy3 staining and Sirius red staining. The key histological difference of the PHMG-p induced liver fibrosis model over existing models, such as $\mathrm{CCl}_{4}$, DDC, bile duct ligation, and HFD, is the development of capsular fibrosis and accumulation of myofibroblasts in the thick fibrotic area. These are advantageous since it is easy to observe myofibroblast activation stemming from mesothelial-mesenchymal transition. Also, PHMG-p induced global changes in the transcriptomic landscape of liver as confirmed by RNAseq analysis. Importantly, many of the biological processes involved in human liver fibrosis were altered such as oxidation-reduction process, mitochondrion morphogenesis, regulation of glucose metabolic process and insulin secretion. This is important since other existing animal liver fibrosis models failed to affect these pathways, highlighting the similarity of PHMG-p induced liver fibrosis to human liver fibrosis.

PHMG-p induced remarkable macroscopic and microscopic changes of liver while other organs including the lung were unaffected. This might be from the poor oral bioavailability of PHMG-p due to its extensive first pass effect (Shim et al., 2018). The round shape of liver in the PHMG-p-injected mouse may be due to the contraction by the fibrosis of liver capsule surrounding the outer part, which would be the direct target of i.p. injected PHMG-p. During mouse embryogenesis, the foregut endoderm pocket, which becomes the liver parenchyma, is formed on embryonic day 9.5. Subsequently, the septum transversum surrounds the liver bud and partially migrates inside the nascent liver to form the capsule layer and portal fibroblasts (Asahina et al., 2011). Recent lineage tracing studies and RNA-sequencing have shown that mesothelial lineage cells located on the surface of the adult liver can re-express the genes related to growth and endothelial-mesenchymal transition following injury, which can give rise to intrahepatic myofibroblasts (Li et al., 2013; Lua et al., 2016; Balog et al., 
A
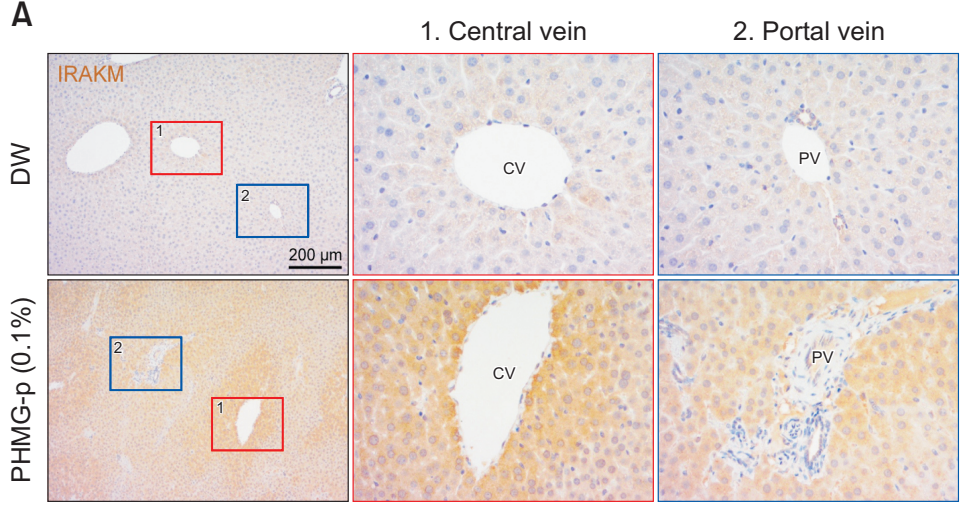

C

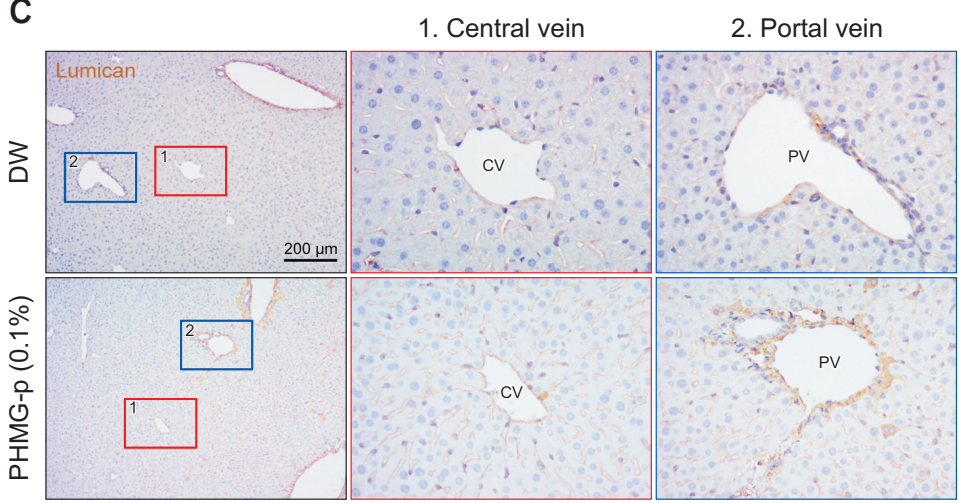

E

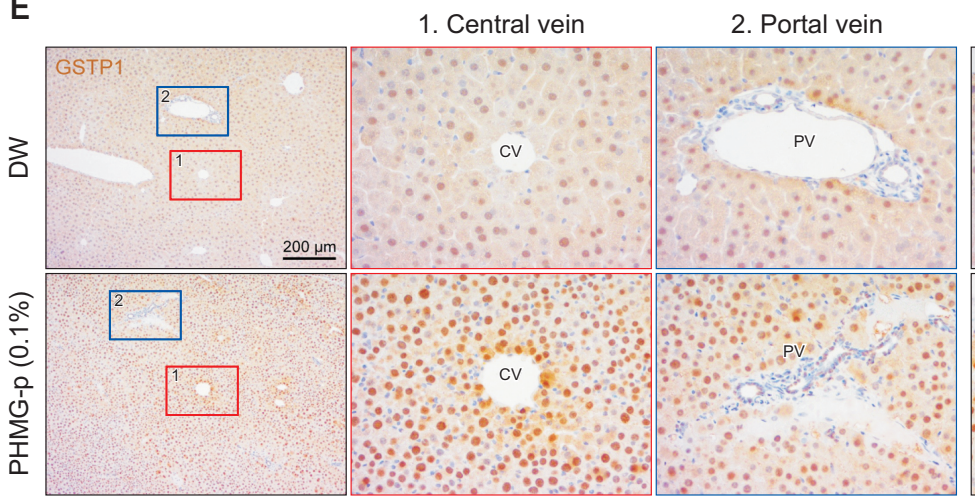

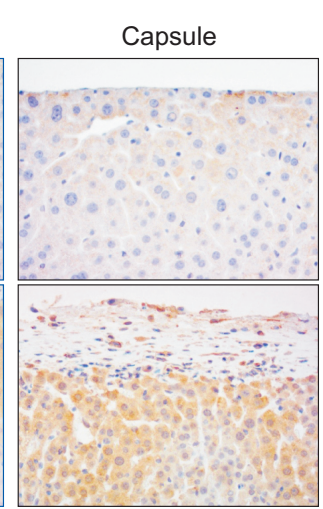

B

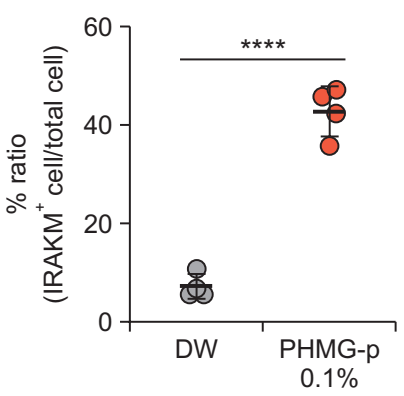

D
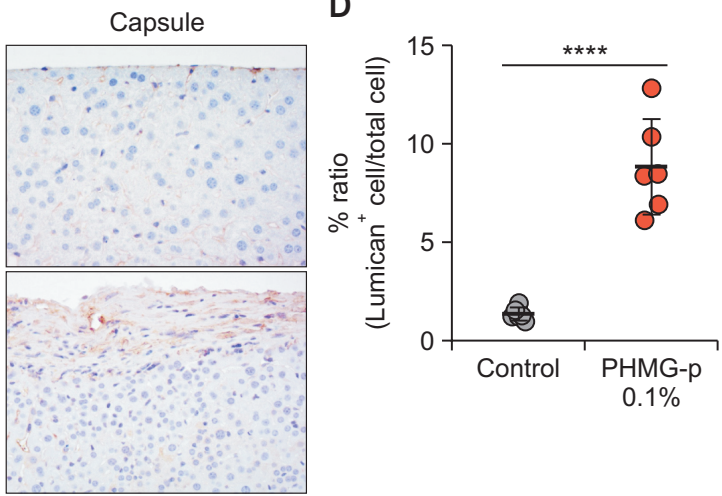

$\mathbf{F}$
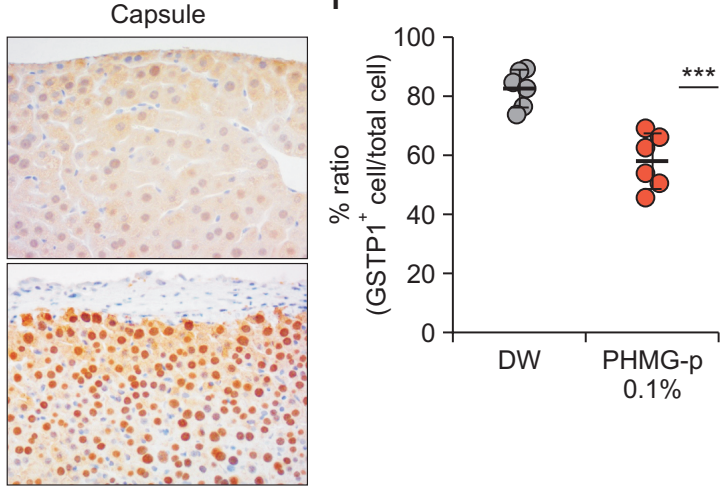

Fig. 6. Immunohistochemistry of IRAKM, Lumican (Lum), and GSTP1 in the mouse liver after PHMG-p 0.1\% exposure. (A) IRAKM in the liver, central vein, portal vein, and capsule regions. (B) IRAKM positive cells/hematoxylin (\%). (C) Lumican in the liver, central vein, portal vein, and capsule regions. (D) Lumican positive cells/hematoxylin (\%). (E) GSTP1 in the liver, central vein, portal vein, and capsule regions. (F) GSTP1-positive cells/hematoxylin (\%). ${ }^{* * *} p<0.001,{ }^{* * *} p<0.0001$.

2020). Unlike Glisson's capsule in mice, the normal human liver capsule has a multilayered structure. In alcohol-induced liver fibrosis in humans, collagen deposition occurs mainly in the sinusoid and central veins; however, collagen deposition and thickening may also occur in the liver capsule (Bataller and Gao, 2015). In addition, capsular fibrosis was observed in human HCV patients (Balog et al., 2020). In our PHMG-p induced liver fibrosis model, the liver surface is primarily affected, and capsular fibrosis occurs remarkably along with the fibrosis of intrahepatic region (especially the periportal region), which would be helpful in understanding distinctive capsular fibrosis in humans.
Hepatocyte necrosis around the periportal area causes fibrosis around the portal vein, which further progresses into fibrosis of the liver sinusoid and ultimately liver cirrhosis. This phenomenon can be observed in HPV B and C infections, which induce inflammatory necrosis around the periportal regions at the initial stage (Phillips and Poucell, 1981; Ishak, 1994). The $\mathrm{CCl}_{4}$-induced liver fibrosis model is one of the most widely used animal models. $\mathrm{CCl}_{4}$ induces liver fibrosis via cytochrome p450-mediated ROS generation and resultant necrosis around the central vein, similar to the alcohol-induced liver damage and fibrosis; however, the periportal region of this model remains relatively normal (Tsukamoto et al., 1990), 
which questions its relevance to human liver fibrotic diseases. Moreover, several animals suffer from pain and die during the first week of $\mathrm{CCl}_{4}$ treatment, and the fibrosis induction is variable according to the physical condition of the animals (McLean et al., 1969). Moreover, $\mathrm{CCl}_{4}$ damages the lungs and kidneys, which further complicates interpretation of the results (Terblanche and Hickman, 1991). Bile duct ligation induces periportal necrosis and results in hepatic fibrosis, but complicated surgery is necessary for model establishment and mortality can reach up to $\sim 50 \%$ (Krahenbuhl et al., 2000). Porcine serum also induces liver fibrosis via evoking an immune reaction but without hepatic necrosis, which is different from HPV-induced liver fibrosis (Bhunchet and Wake, 1992). Dietinduced models such as a high-fat diet, methionine cholinedeficient diet, or the Lieber-Decarli alcoholic diet require a long time to establish fibrosis with significant individual differences in the extent of fibrosis. In this regard, the PHMG-p-induced fibrosis model, which can be established within 5 weeks without causing animal death, and with small individual variation in the degree of fibrosis, would be an excellent mouse model of liver fibrosis for simulating HPV-induced liver fibrosis.

PHMG-p kills bacteria by inhibiting dehydrogenases and impairing bacterial membrane function (Brzezinska et al., 2018). Unexpectedly, inhalation of PHMG-p via aerosol induces necrosis and hypertrophy of the bronchiolar epithelium, inflammatory cell infiltration, mucin secretion, and eventually fibrosis of the lung. PHMG-p induces apoptosis, endoplasmic reticulum stress, and autophagy, along with increased secretion of the inflammatory cytokines IL- $1 \beta$ and IL- 6 and the chemokines $\mathrm{C}-\mathrm{X}-\mathrm{C}$ motif and $\mathrm{CXCL} 1$. Expression of fibrotic markers is also elevated, including that of monocyte chemoattractant protein 1, fibronectin, matrix metalloproteinase (MMP)2, MMP12, and TIMP1. The PHMG-p-induced lung fibrosis is attributed to the ROS production and damage to the airway barrier, which triggers inflammation and ECM accumulation in the lungs via the nuclear factor-kappa B pathway. Although the mechanisms underlying liver fibrosis remain to be fully understood, several studies have demonstrated the critical role of oxidative stress in the activation of HSCs (Lee et al., 1995; FernandezCheca et al., 1998). In chronic liver injury and fibrogenesis, ROS cause cellular damage and trigger signal transduction pathway to generate the key mediators of fibrosis (PDGF and TGF- $\beta$ ), which activate HSCs to produce ECM (Sundaresan et al., 1995; Lander, 1997; Finkel, 1998; Thannickal et al., 2000). These observations suggest that PHMG-p induces liver fibrosis by promoting ROS generation and subsequent events leading to inflammation and fibrogenesis. Indeed, our study revealed the alteration of oxidation-reduction processes and downregulation of GSTp1 and GSTp2 expression in the livers of mice treated with PHMG-p.

Many of the biological pathways altered in liver fibrosis were affected by PHMG-p i.p. injection. The oxidation-reduction process is altered in human liver fibrosis (Diamond et al., 2007), which was supported by studies using HSCs (Bonacchi et al., 2003; De Minicis and Brenner, 2007; Wobser et al., 2009; Guimaraes et al., 2010) and in other animal models of liver fibrosis. Furthermore, PHMG-p broadly affect metabolic pathways of lipids, which are altered in human liver fibrosis (Diamond et al., 2007) and in HSCs in vitro (Bechmann et al., 2009; Wobser et al., 2009). In addition, epoxygenase P450 pathway (Mann and Mann, 2009), steroid biosynthetic process (Song et al., 2013), negative regulation of gluconeogen- esis (Liu et al., 2017), positive regulation of glucose metabolic process (Nishikawa et al., 2014), negative regulation of insulin secretion involved in the cellular response to glucose stimulus (Ippolito et al., 2016), arachidonic acid metabolic process (Dong et al., 2016), mitochondrion morphogenesis (Diamond et al., 2007), glucose homeostasis (Gao et al., 2017), and response to drugs (Dong et al., 2016) have been identified as liver fibrosis-related pathways in human. Many of these pathways are not affected in the existing animal fibrosis models, supporting that PHMG-p-induced liver fibrosis may be a good alternative to study human liver fibrosis.

Expression levels of lumican and IRAK3, which are closely involved in the pathogenesis of liver fibrosis, increased in the liver following PHMG-p treatment in a dose-dependent manner. Lumican, the pivotal keratan sulfate proteoglycan in the cornea, is mainly expressed in the mesenchymal tissues in the body, constituting a crucial component of the ECM (Chakravarti, 2002). In liver fibrosis, lumican regulates the assembly of collagen fibers and activates TGF- $\beta$ and SMA. Moreover, upregulated lumican expression is observed in patients with nonalcoholic fatty liver disease and non-alcoholic steatohepatitis, substantiating its role in liver fibrosis (Charlton et al., 2009; Barbariga et al., 2019; Mohammadzadeh et al., 2019; Chang et al., 2021). In our study, II1r2 and Irak3 emerged as the most strongly affected genes following PHMG-p treatment. IL1R2 is a decoy receptor for members of IL1 family, and sequesters IL1 $\alpha$, IL1 $\beta$, and IL1Ra to modulate their signal transduction pathways (Lang et al., 1998). In contrast, IRAKs (IRAK1-4) are serine-threonine kinases involved in the signaling pathways associated with Toll-like receptor and IL-1, modulating immune responses and inflammation. IRAKs play a key role in cancer and in metabolic and inflammatory diseases, and their suppression has been proposed as a therapeutic strategy for these diseases (Singer et al., 2018). IRAK3 (also called IRAK-M) is also important for the maintenance and repair of endothelial barrier function after lung injury (Soni et al., 2018) and involved in the modulation of innate immunity, of which deficiency increased the monocyte sensitization to produce TNF- $\alpha$ in human cirrhosis (Tazi et al., 2006). Furthermore, deficiency of IRAK-M aggravated the liver injury in the alcoholic liver injury model (Wang et al., 2013), suggesting its role in human fibrosis.

In summary we developed PHMG-p-induced liver fibrosis model in male C57/BL6 mice. Histology, staining for collagen, immunohistochemistry for $\alpha$-SMA and collagen, and PCR analysis of fibrotic genes (Acta2, Col1a1, and Timp1) confirmed the PHMG-induced liver fibrosis in the peri-central, peri-portal, and capsule regions. Furthermore, RNA-sequencing analysis revealed that several biological pathways and genes related to human liver fibrosis were altered by PHMG-p. These results suggest that the PHMG-p-induced liver fibrosis model can be employed to study human liver fibrosis.

\section{CONFLICT OF INTEREST}

The authors declare no conflicts of interest.

\section{ACKNOWLEDGMENTS}

K.M.L. is supported by National Research Founda- 
tion (NRF) funded by Ministry of Science and ICT (MSIT) (2018R1A5A2025286). K.T.N. is supported by the Korea Mouse Phenotyping Project (NRF-2016M3A9D5A01952416).

\section{REFERENCES}

Albanis, E. and Friedman, S. L. (2006) Antifibrotic agents for liver disease. Am. J. Transplant. 6, 12-19.

Asahina, K., Zhou, B., Pu, W. T. and Tsukamoto, H. (2011) Septum transversum-derived mesothelium gives rise to hepatic stellate cells and perivascular mesenchymal cells in developing mouse liver. Hepatology 53, 983-995.

Asiedu-Gyekye, I. J., Mahmood, S. A., Awortwe, C. and Nyarko, A. K. (2014) A preliminary safety evaluation of polyhexamethylene guanidine hydrochloride. Int. J. Toxicol. 33, 523-531.

Balog, S., Li, Y., Ogawa, T., Miki, T., Saito, T., French, S. W. and Asahina, K. (2020) Development of capsular fibrosis beneath the liver surface in humans and mice. Hepatology 71, 291-305.

Barbariga, M., Vallone, F., Mosca, E., Bignami, F., Magagnotti, C., Fonteyne, P., Chiappori, F., Milanesi, L., Rama, P., Andolfo, A. and Ferrari, G. (2019) The role of extracellular matrix in mouse and human corneal neovascularization. Sci. Rep. 9, 14272.

Bataller, R. and Gao, B. (2015) Liver fibrosis in alcoholic liver disease. Semin. Liver Dis. 35, 146-156.

Bechmann, L. P., Zahn, D., Gieseler, R. K., Fingas, C. D., Marquitan, G., Jochum, C., Gerken, G., Friedman, S. L. and Canbay, A. (2009) Resveratrol amplifies profibrogenic effects of free fatty acids on human hepatic stellate cells. Hepatol. Res. 39, 601-608.

Bhunchet, E. and Wake, K. (1992) Role of mesenchymal cell populations in porcine serum-induced rat liver fibrosis. Hepatology 16, 1452-1473.

Bindea, G., Mlecnik, B., Hackl, H., Charoentong, P., Tosolini, M., Kirilovsky, A., Fridman, W. H., Pages, F., Trajanoski, Z. and Galon, J. (2009) ClueGO: a Cytoscape plug-in to decipher functionally grouped gene ontology and pathway annotation networks. Bioinformatics 25, 1091-1093.

Bonacchi, A., Petrai, I., Defranco, R. M., Lazzeri, E., Annunziato, F., Efsen, E., Cosmi, L., Romagnani, P., Milani, S., Failli, P., Batignani, G., Liotta, F., Laffi, G., Pinzani, M., Gentilini, P. and Marra, F. (2003) The chemokine CCL21 modulates lymphocyte recruitment and fibrosis in chronic hepatitis C. Gastroenterology 125, 1060-1076.

Brzezinska, M. S., Walczak, M., Jankiewicz, U. and Pejchalová, M. (2018) Antimicrobial activity of polyhexamethylene guanidine derivatives introduced into polycaprolactone. J. Polym. Environ. 26, 589-595.

Chakravarti, S. (2002) Functions of lumican and fibromodulin: lessons from knockout mice. Glycoconj. J. 19, 287-293.

Chang, Y., He, J., Xiang, X. and Li, H. (2021) LUM is the hub gene of advanced fibrosis in nonalcoholic fatty liver disease patients. Clin. Res. Hepatol. Gastroenterol. 45, 101435.

Charlton, M., Viker, K., Krishnan, A., Sanderson, S., Veldt, B., Kaalsbeek, A. J., Kendrick, M., Thompson, G., Que, F., Swain, J. and Sarr, M. (2009) Differential expression of lumican and fatty acid binding protein-1: new insights into the histologic spectrum of nonalcoholic fatty liver disease. Hepatology 49, 1375-1384.

De Minicis, S. and Brenner, D. A. (2007) NOX in liver fibrosis. Arch. Biochem. Biophys. 462, 266-272.

Diamond, D. L., Jacobs, J. M., Paeper, B., Proll, S. C., Gritsenko, M. A., Carithers, R. L., Jr., Larson, A. M., Yeh, M. M., Camp, D. G., 2nd, Smith, R. D. and Katze, M. G. (2007) Proteomic profiling of human liver biopsies: hepatitis $C$ virus-induced fibrosis and mitochondrial dysfunction. Hepatology 46, 649-657.

Dong, S., Chen, Q. L., Song, Y. N., Sun, Y., Wei, B., Li, X. Y., Hu, Y. Y., Liu, P. and Su, S. B. (2016) Mechanisms of CCl4-induced liver fibrosis with combined transcriptomic and proteomic analysis. J. Toxicol. Sci. 41, 561-572.

elSisi, A. E., Hall, P., Sim, W. L., Earnest, D. L. and Sipes, I. G. (1993) Characterization of vitamin A potentiation of carbon tetrachlorideinduced liver injury. Toxicol. Appl. Pharmacol. 119, 280-288.

Fernandez-Checa, J. C., Kaplowitz, N., Garcia-Ruiz, C. and Colell, A.
(1998) Mitochondrial glutathione: importance and transport. Semin. Liver Dis. 18, 389-401.

Finkel, T. (1998) Oxygen radicals and signaling. Curr. Opin. Cell Biol. $10,248-253$

Gao, J., Qin, X. J., Jiang, H., Chen, J. F., Wang, T., Zhang, T., Xu, S. $Z$. and Song, J. M. (2017) Detecting serum and urine metabolic profile changes of CCl4-liver fibrosis in rats at 12 weeks based on gas chromatography-mass spectrometry. Exp. Ther. Med. 14, 1496-1504.

Gentleman, R. C., Carey, V. J., Bates, D. M., Bolstad, B., Dettling, M., Dudoit, S., Ellis, B., Gautier, L., Ge, Y., Gentry, J., Hornik, K., Hothorn, T., Huber, W., lacus, S., Irizarry, R., Leisch, F., Li, C., Maechler, M., Rossini, A. J., Sawitzki, G., Smith, C., Smyth, G., Tierney, L., Yang, J. Y. and Zhang, J. (2004) Bioconductor: open software development for computational biology and bioinformatics. Genome Biol. 5, R80.

George, J., Tsuchishima, M. and Tsutsumi, M. (2019) Molecular mechanisms in the pathogenesis of $\mathrm{N}$-nitrosodimethylamine induced hepatic fibrosis. Cell Death Dis. 10, 18.

Guimaraes, E. L., Empsen, C., Geerts, A. and van Grunsven, L. A. (2010) Advanced glycation end products induce production of reactive oxygen species via the activation of NADPH oxidase in murine hepatic stellate cells. J. Hepatol. 52, 389-397.

Ippolito, D. L., AbdulHameed, M. D., Tawa, G. J., Baer, C. E., Permenter, M. G., McDyre, B. C., Dennis, W. E., Boyle, M. H., Hobbs, C. A., Streicker, M. A., Snowden, B. S., Lewis, J. A., Wallqvist, A. and Stallings, J. D. (2016) Gene expression patterns associated with histopathology in toxic liver fibrosis. Toxicol. Sci. 149, 67-88.

Ishak, K. G. (1994) Chronic hepatitis: morphology and nomenclature. Mod. Pathol. 7, 690-713.

Ismail, M. H. and Pinzani, M. (2009) Reversal of liver fibrosis. Saudi J. Gastroenterol. 15, 72-79.

Iwaisako, K., Jiang, C., Zhang, M., Cong, M., Moore-Morris, T. J., Park, T. J., Liu, X., Xu, J., Wang, P., Paik, Y. H., Meng, F., Asagiri, M., Murray, L. A., Hofmann, A. F., lida, T., Glass, C. K., Brenner, D. A. and Kisseleva, T. (2014) Origin of myofibroblasts in the fibrotic liver in mice. Proc. Natl. Acad. Sci. U.S.A. 111, E3297-E3305.

Jiao, X., Sherman, B. T., Huang da, W., Stephens, R., Baseler, M. W., Lane, H. C. and Lempicki, R. A. (2012) DAVID-WS: a stateful web service to facilitate gene/protein list analysis. Bioinformatics 28, 1805-1806.

Kanehisa, M. and Goto, S. (2000) KEGG: Kyoto Encyclopedia of Genes and Genomes. Nucleic Acids Res. 28, 27-30.

Kim, H. R., Lee, K., Park, C. W., Song, J. A., Shin, D. Y., Park, Y. J. and Chung, K. H. (2016) Polyhexamethylene guanidine phosphate aerosol particles induce pulmonary inflammatory and fibrotic responses. Arch. Toxicol. 90, 617-632.

Krahenbuhl, S., Brass, E. P. and Hoppel, C. L. (2000) Decreased carnitine biosynthesis in rats with secondary biliary cirrhosis. Hepatology 31, 1217-1223.

Lander, H. M. (1997) An essential role for free radicals and derived species in signal transduction. FASEB J. 11, 118-124.

Lang, D., Knop, J., Wesche, H., Raffetseder, U., Kurrle, R., Boraschi, D. and Martin, M. U. (1998) The type II IL-1 receptor interacts with the IL-1 receptor accessory protein: a novel mechanism of regulation of IL-1 responsiveness. J. Immunol. 161, 6871-6877.

Langmead, B. and Salzberg, S. L. (2012) Fast gapped-read alignment with Bowtie 2. Nat. Methods 9, 357-359.

Lee, K. S., Buck, M., Houglum, K. and Chojkier, M. (1995) Activation of hepatic stellate cells by TGF alpha and collagen type I is mediated by oxidative stress through c-myb expression. J. Clin. Invest. 96, 2461-2468.

Li, Y., Wang, J. and Asahina, K. (2013) Mesothelial cells give rise to hepatic stellate cells and myofibroblasts via mesothelial-mesenchymal transition in liver injury. Proc. Natl. Acad. Sci. U.S.A. 110, 2324-2329.

Liu, X., Dai, R., Ke, M., Suheryani, I., Meng, W. and Deng, Y. (2017) Differential proteomic analysis of dimethylnitrosamine (dmn)-induced liver fibrosis. Proteomics 17, 1700267.

Lua, I., Li, Y., Zagory, J. A., Wang, K. S., French, S. W., Sevigny, J. and Asahina, K. (2016) Characterization of hepatic stellate cells, portal fibroblasts, and mesothelial cells in normal and fibrotic livers. $J$. 
Hepatol. 64, 1137-1146.

Mann, J. and Mann, D. A. (2009) Transcriptional regulation of hepatic stellate cells. Adv. Drug Deliv. Rev. 61, 497-512.

McLean, E. K., McLean, A. E. and Sutton, P. M. (1969) Instant cirrhosis. An improved method for producing cirrhosis of the liver in rats by simultaneous administration of carbon tetrachloride and phenobarbitone. Br. J. Exp. Pathol. 50, 502-506.

Mederacke, I., Hsu, C. C., Troeger, J. S., Huebener, P., Mu, X., Dapito, D. H., Pradere, J. P. and Schwabe, R. F. (2013) Fate tracing reveals hepatic stellate cells as dominant contributors to liver fibrosis independent of its aetiology. Nat. Commun. 4, 2823.

Mohammadzadeh, N., Lunde, I. G., Andenaes, K., Strand, M. E., Aronsen, J. M., Skrbic, B., Marstein, H. S., Bandlien, C., Nygard, S., Gorham, J., Sjaastad, I., Chakravarti, S., Christensen, G., Engebretsen, K. V. T. and Tonnessen, T. (2019) The extracellular matrix proteoglycan lumican improves survival and counteracts cardiac dilatation and failure in mice subjected to pressure overload. Sci. Rep. 9, 9206.

Nishikawa, T., Bellance, N., Damm, A., Bing, H., Zhu, Z., Handa, K., Yovchev, M. I., Sehgal, V., Moss, T. J., Oertel, M., Ram, P. T., Pipinos, II, Soto-Gutierrez, A., Fox, I. J. and Nagrath, D. (2014) A switch in the source of ATP production and a loss in capacity to perform glycolysis are hallmarks of hepatocyte failure in advance liver disease. J. Hepatol. 60, 1203-1211.

Park, D. (2013) Review of humidifier lung cases caused by use of humidifier-focusing on probable environmental causal agents. Korean J. Environ. Health Sci. 39, 105-116.

Phillips, M. J. and Poucell, S. (1981) Modern aspects of the morphology of viral hepatitis. Hum. Pathol. 12, 1060-1084.

Quinlan, A. R. and Hall, I. M. (2010) BEDTools: a flexible suite of utilities for comparing genomic features. Bioinformatics 26, 841-842.

Saeed, A. I., Sharov, V., White, J., Li, J., Liang, W., Bhagabati, N., Braisted, J., Klapa, M., Currier, T., Thiagarajan, M., Sturn, A., Snuffin, M., Rezantsev, A., Popov, D., Ryltsov, A., Kostukovich, E., Borisovsky, I., Liu, Z., Vinsavich, A., Trush, V. and Quackenbush, J. (2003) TM4: a free, open-source system for microarray data management and analysis. Biotechniques 34, 374-378.

Schuppan, D. and Afdhal, N. H. (2008) Liver cirrhosis. Lancet 371, 838-851.

Shim, H. E., Lee, J. Y., Lee, C. H., Mushtaq, S., Song, H. Y., Song, L., Choi, S. J., Lee, K. and Jeon, J. (2018) Quantification of inhaled aerosol particles composed of toxic household disinfectant using radioanalytical method. Chemosphere 207, 649-654.

Singer, J. W., Fleischman, A., Al-Fayoumi, S., Mascarenhas, J. O.,
Yu, Q. and Agarwal, A. (2018) Inhibition of interleukin-1 receptorassociated kinase 1 (IRAK1) as a therapeutic strategy. Oncotarget 9, 33416-33439.

Solodun, Y. V., Monakhova, Y. B., Kuballa, T., Samokhvalov, A. V., Rehm, J. and Lachenmeier, D. W. (2011) Unrecorded alcohol consumption in Russia: toxic denaturants and disinfectants pose additional risks. Interdiscip. Toxicol. 4, 198-205.

Song, G., Hu, C., Zhu, H., Li, X., Zhao, L., Zhou, R., Zhang, X., Zhang, F., Wu, L. and Li, Y. (2013) Comparative proteomics study on liver mitochondria of primary biliary cirrhosis mouse model. BMC Gastroenterol. 13, 64.

Song, J., Jung, K. J., Yang, M. J., Han, S. C. and Lee, K. (2021) Assessment of acute and repeated pulmonary toxicities of oligo(2-(2ethoxy)ethoxyethyl guanidium chloride in mice. Toxicol. Res. 37, 99-113.

Soni, D., Wang, D. M., Regmi, S. C., Mittal, M., Vogel, S. M., Schluter, D. and Tiruppathi, C. (2018) Deubiquitinase function of A20 maintains and repairs endothelial barrier after lung vascular injury. Cell Death Discov. 4, 60

Sundaresan, M., Yu, Z. X., Ferrans, V. J., Irani, K. and Finkel, T. (1995) Requirement for generation of $\mathrm{H} 2 \mathrm{O} 2$ for platelet-derived growth factor signal transduction. Science 270, 296-299.

Tazi, K. A., Quioc, J. J., Saada, V., Bezeaud, A., Lebrec, D. and Moreau, R. (2006) Upregulation of TNF-alpha production signaling pathways in monocytes from patients with advanced cirrhosis: possible role of Akt and IRAK-M. J. Hepatol. 45, 280-289.

Terblanche, J. and Hickman, R. (1991) Animal models of fulminant hepatic failure. Dig. Dis. Sci. 36, 770-774.

Thannickal, V. J., Day, R. M., Klinz, S. G., Bastien, M. C., Larios, J. M. and Fanburg, B. L. (2000) Ras-dependent and -independent regulation of reactive oxygen species by mitogenic growth factors and TGF-beta1. FASEB J. 14, 1741-1748.

Tsukamoto, H., Matsuoka, M. and French, S. W. (1990) Experimental models of hepatic fibrosis: a review. Semin. Liver Dis. 10, 56-65.

Wang, Y., Hu, Y., Chao, C., Yuksel, M., Colle, I., Flavell, R. A., Ma, Y., Yan, H. and Wen, L. (2013) Role of IRAK-M in alcohol induced liver injury. PLOS ONE 8, e57085.

Wobser, H., Dorn, C., Weiss, T. S., Amann, T., Bollheimer, C., Buttner, R., Scholmerich, J. and Hellerbrand, C. (2009) Lipid accumulation in hepatocytes induces fibrogenic activation of hepatic stellate cells. Cell Res. 19, 996-1005.

Yasuda, M., Shimizu, I., Shiba, M. and Ito, S. (1999) Suppressive effects of estradiol on dimethylnitrosamine-induced fibrosis of the liver in rats. Hepatology 29, 719-727. 